\title{
Structural and Transport Properties of Fine CoTi-ZnBaM Hexagonal Ferrite
}

\author{
M. R. Eraky \\ Physics Department, Faculty of Science, Kafrelsheikh University, 33516 El Geesh Street, Kafr El Sheikh, Egypt
}

\begin{abstract}
A series of polycrystalline samples of the system $B a_{1-x} \mathrm{Zn}_{x} \mathrm{Co}_{x} \mathrm{Ti}_{x} \mathrm{Fe}_{12-2 x} \mathrm{O}_{19}(x=0.0,0.2,0.4$ and 0.6$)$ were prepared by the usual ceramic technique. X-ray diffraction, thermal conductivity, thermoelectric power, drift mobility and phonon frequency were studied for the samples. The X-ray diffraction pattern confirms the presence single phase magnetoplumbite structure of substituted $M$ ferrite samples. The thermal conductivity and thermoelectric power were determined at different temperatures for all the samples. The thermal conductivity coefficient, $k$, increases with increasing temperature due to the increasing in the number of photons, whereas the decreasing in, $k$, with increases doping ratio may be due to the formation of anion vacancies. The thermo-electric power measurements reveal the p-type semiconducting behavior of the samples. The increasing in drift mobility with temperature indicates that the hopping of electrons between $\mathrm{Fe}^{3+}-\mathrm{Fe}^{2+}$ and holes $\mathrm{Co}^{2+}-\mathrm{Co}^{3+}$ are activated by temperature as well as its concentration. So, it is presumed here that the conduction mechanism depends on the hopping of localized charge carriers. Due to the less value of activation energy $(<0.3 e$ $V)$ small polaron hopping can be ruled out from conduction process. Thermoelectric power data indicated that the band conduction theory can be participating in the conduction mechanism. The phonon frequency was estimated to have an optimum value for higher substitution, due to the increase in phonon scattering.
\end{abstract}

Keywords: Thermal conductivity, Phonon frequency, Drift mobility, M hexagonal ferrite, Transport properties.

\section{Introduction}

Today ceramic magnetic materials, capable of combining a high resistivity and a high permeability, are found in numerous products used in our every day life such as home appliances, electronic devices, communication equipments and computers [1]. Polycrystalline ferrites are good magnetic semiconductors with low electrical conductivity and low eddy currents. They play an important role in various technological applications from microwave to radio wave frequencies. They are important components for the latest products, such as cellular phones, video cameras, and notebook computers hard and floppy drives. Hexaferrites powder with a narrow size distribution are promising materials for industrial applications due to their high coercivity, their moderate saturation magnetization, large magnetocrystalline anisotropy, high Curie temperature, chemical stability and corrosion resistivity [2-5].

$\mathrm{BaM}$ ferrite has a hexagonal ferrite structure $(\mathrm{P} 63 / \mathrm{mmc})$ which is symbolically described by $\mathrm{RSR}^{*} \mathrm{~S}^{*}$, where $\mathrm{R}$ is a three oxygen - layer block with composition $\mathrm{BaFe}_{6} \mathrm{O}_{11}, \mathrm{~S}$ (spinel block) is a two - oxygen - layer block with composition $\mathrm{Fe}_{6} \mathrm{O}_{8}$, and the asterisk means that the corresponding block has been rotated by $180^{\circ}$ around the hexagonal $\mathrm{c}$ axis. In this structure the $\mathrm{Fe}^{3+}$ ions are distributed among five different sites (sub-lattice). These sites have different coordinations and are designated: octahedral (12k, 2a and $4 \mathrm{f} 2$ sites), tetrahedral (4f1 site) and trigonal bi-pyramid ( $2 \mathrm{~b}$ site). Our previous studies on the substituted CaSrM ferrite shows the effect of Co-Ti and temperature on the electrical and thermal character for this type of ferrite [6]. The aim of the present work is to study the structural, thermal and electrical properties for $\mathrm{BaM}$ hexaferrite when both diamagnetic $\mathrm{Ba}^{2+}$ and magnetic $\mathrm{Fe}^{3+}$ ions are substituted by $\mathrm{Zn}$ and $\mathrm{Co}$ and Ti respectively $\left[\mathrm{Ba}_{1}\right.$. $\left.{ }_{x} \mathrm{Zn}_{\mathrm{x}} \mathrm{Co}_{\mathrm{x}} \mathrm{Ti}_{\mathrm{x}} \mathrm{Fe}_{12-2 \mathrm{x}} \mathrm{O}_{19}(\mathrm{x} \leq 0.6)\right]$.

\section{Materials and Methods}

The oxides $\mathrm{ZnO}, \mathrm{CoO}, \mathrm{TiO}_{2}, \mathrm{Fe}_{2} \mathrm{O}_{3}$ and $\mathrm{BaCO}_{3}$ ( high purity) were mixed together with molecular weight ratio for the preparation of $\mathrm{Ba}_{1-\mathrm{x}} \mathrm{Zn} \quad \mathrm{x}^{\mathrm{x}} \quad \mathrm{Co}_{\mathrm{x}} \mathrm{Ti}_{\mathrm{x}} \mathrm{Fe}_{12-2 \mathrm{x}} \mathrm{O}_{19} \quad(0 \leq \mathrm{x} \leq 0.6)$ hexaferrite by the conventional ceramic technique. Pure oxides were weighed using a digital balance, then ground to a very fine powder and mixed with distilled water for 4 hours using a magnetic stirrer. The mixture was subsequently dried at $120{ }^{\circ} \mathrm{C}$ and then grounded in an agate mortar to obtain a very fine powder. All mixtures were pre-sintered at $1150{ }^{\circ} \mathrm{C}$ for 4 hours and quenched to room temperature. The samples were re-grinded for $8 \mathrm{~h}$. The final fine powders were compressed into pellets (disks) using a hydraulic press under 75 bar for $2-3 \mathrm{~min}$. All the samples were then finally sintered at $1230{ }^{\circ} \mathrm{C}$ for 6 hours and slowly cooled to room temperature. The samples were polished to obtain a uniform parallel surface. Contacts on the sample surface were made by silver paste. The bulk density of the tablets turns out to be $=4.82 \sim 5.06 \mathrm{~g} . \mathrm{cm}^{-3}$. The X-ray diffractograms were recorded with a Siemens D-5000 X-ray diffractometer using CoKa radiation. The details of electrical and thermal measurements were reported earlier $[6,7]$.

\section{Results and Discussion}

\subsection{X- Ray Diffraction}

The X-ray diffraction patterns of the $\mathrm{Ba}_{1-x} \mathrm{Zn}_{x} \mathrm{Co}_{x} \mathrm{Ti}_{\mathrm{x}} \mathrm{Fe}_{12-}$ ${ }_{2 x} \mathrm{O}_{19}$ samples are shown in Fig. 1. They demonstrate that all the samples of this series have single phase magnetoplumbite structure, and no trace of other phases was detected. On the other hand sharp lines are observed in all samples, indicating that the microstructure of the samples is composed of poly crystallites with a relatively large size. The lattice constants 'a', ' $c$ ' and their ratio c/a are slightly increase monotonically with increasing $\mathrm{x}$ as shown in Table 1 . This is in accordance 


\section{International Journal of Science and Research (IJSR) \\ ISSN (Online): 2319-7064 \\ Index Copernicus Value (2013): 6.14 | Impact Factor (2014): 5.611}

with the fact that all hexagonal classes (M-Y-and W-type) are characterized by a constant lattice parameter 'a' (of order 5.88 $\AA$ ) but the parameter ' $c$ ' is slightly varied [3]. The change in the relative intensities may be ascribed to the occupation of the lattice sites by different substituted ions.

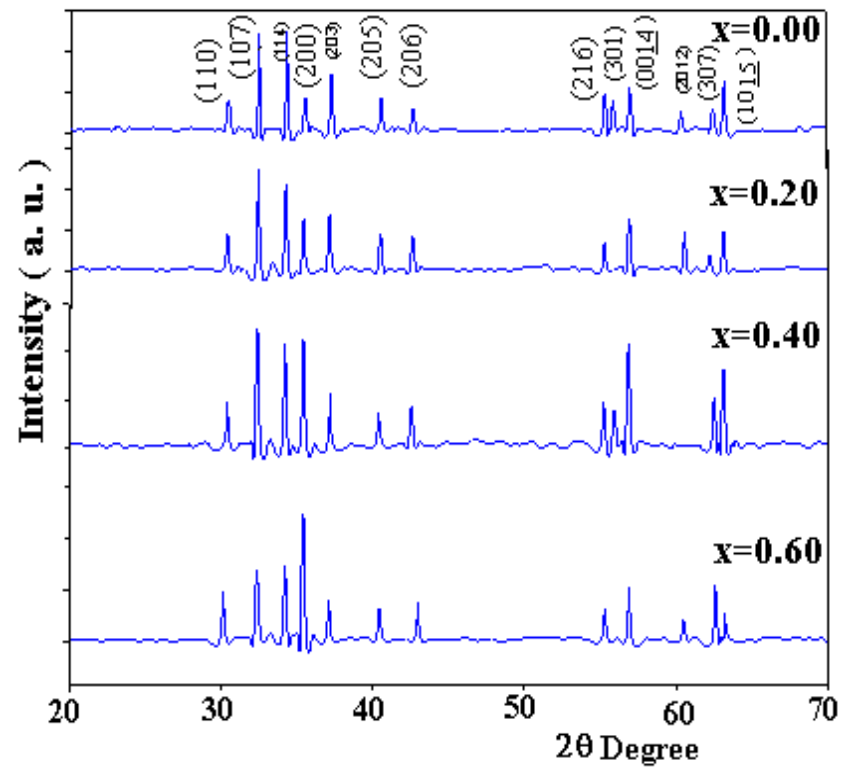

Figure 1: XRD for CoTi-BaZnM hexagonal ferrite system

\subsection{The Thermal Conductivity Coefficient (k)}

The thermal conductivity coefficient, $k$, for the samples was estimated via the formula :

$$
\mathrm{Q}=\frac{\mathrm{IV}}{\mathrm{J}}=\mathrm{kA} \cdot \mathrm{dT} / \mathrm{dt}
$$

where $\mathrm{Q}$ is the quantity of heat transferred through the sample per unit time, $\mathrm{I}$ is the electric current in Ampere, $\mathrm{V}$ is the applied voltage in Volt, $\mathrm{A}$ is the cross-section area of the sample and (dT/dt) is the temperature gradient on the sample. The variation in the thermal coefficient, $\mathrm{k}$, with the compositional parameter (x) at 350,450 and $550 \mathrm{~K}$ are shown in Fig. 2. The thermal conductivity, $k$, decreases with increasing $\mathrm{x}$. It has been suggested that doping decreases the concentration of lattice vacancies [8]. The formation of excess vacancies enhances the volume of diffusion mechanism. However, if excess vacancies are formed, these would be anion vacancies rather than cation vacancies since $\mathrm{Co}^{2+}$ ion has a lower charge than the $\mathrm{Fe}^{3+}$ ion. These vacancies act as centers of phonon scattering caused a decrease in the coefficient of thermal conductivity, $k$. There are clear increases in the values of, $\mathrm{k}$, with increasing in temperature. This behavior is attributed to the increasing in the number of photons with temperature, thereby leading to the increase in thermal conductivity.

Table 1: Crystal lattice parameters and the activation energy for CoTiZnBaM hexaferite

\begin{tabular}{|c|c|c|c|c|}
\hline Composition, $x$ & $a(\AA)$ & $c(\AA)$ & $c / a$ & $\Delta E(\mathrm{eV})$ \\
\hline 0.0 & 5.872 & 23.210 & 3.952 & 0.132 \\
\hline 0.2 & 5.891 & 23.241 & 3.945 & 0.125 \\
\hline 0.4 & 5.904 & 23.262 & 3.940 & 0.148 \\
\hline 0.6 & 5.895 & 23.295 & 3.952 & 0.145 \\
\hline
\end{tabular}

\subsection{Effect of Temperature and Composition on the} Thermoelectric Power $(\alpha)$

The thermoelectric power or Seebeck coefficient $(\boldsymbol{\alpha})$ for $\mathrm{Ba}_{1}$ ${ }_{\mathrm{x}} \mathrm{Zn}_{\mathrm{x}} \mathrm{Co}_{\mathrm{x}} \mathrm{Ti}_{\mathrm{x}} \mathrm{Fe}_{12-2 \mathrm{x}} \mathrm{O}_{19}$ ferrite increases by increasing temperature and compositional parameter, $\mathrm{x}$, as shown in Fig. 3 . This means that the dominating charge carriers are holes and the minority conduction process is due to impurities. The behavior $\alpha(\mathrm{T}, \square \mathrm{x})$ may be explained as follows: doping is another mechanism for introducing vacancies [9-11].

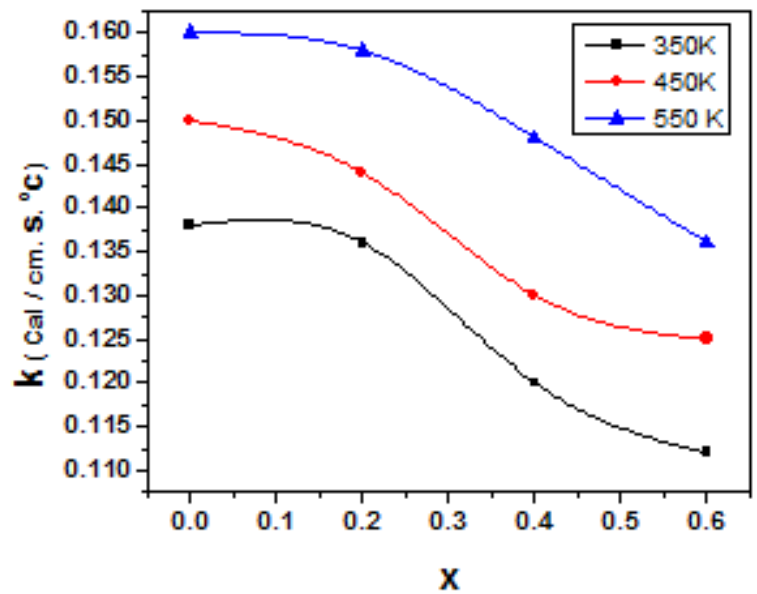

Figure 2: Variation of thermal conductivity coefficient with Co contents at different temperature

When the temperature increases the concentration of generating charge carriers increase and the hopping of these charge carriers induce charged vacancies. The excess vacancies which are formed causes a reduction for the phonon scattered, leading to a noticeable increase in the thermo-electric power.

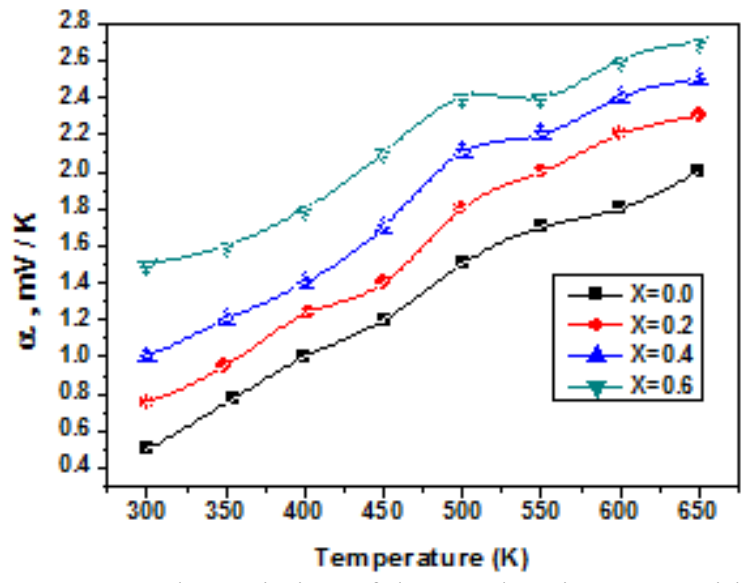

Figure 3: The variation of thermoelectric power with temperature for $\mathrm{Ba}_{1-\mathrm{x}} \mathrm{Zn}_{\mathrm{x}} \mathrm{Co}_{\mathrm{x}} \mathrm{Ti}_{\mathrm{x}} \mathrm{Fe}_{12-2 \mathrm{x}} \mathrm{O}_{19}$ hexaferite 


\section{International Journal of Science and Research (IJSR) \\ ISSN (Online): 2319-7064}

Index Copernicus Value (2013): 6.14 | Impact Factor (2014): 5.611

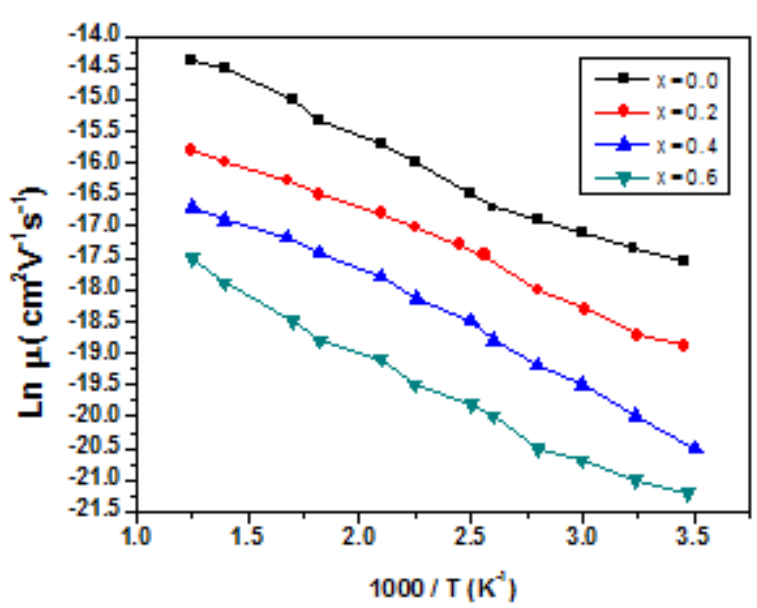

Figure 4: Tamperature dependence of drift mobility for $\mathrm{Ba}_{1-}$ ${ }_{\mathrm{x}} \mathrm{Zn}_{\mathrm{x}} \mathrm{Co}_{\mathrm{x}} \mathrm{Ti}_{\mathrm{x}} \mathrm{Fe}_{12-2 \mathrm{x}} \mathrm{O}_{19}$ hexaferite

\subsection{Temperature Dependence the Charge Carrier Mobility $(\mu)$}

It seems that the system $\mathrm{Ba}_{1-\mathrm{x}} \mathrm{Zn}_{\mathrm{x}} \mathrm{Co}_{\mathrm{x}} \mathrm{Ti}_{\mathrm{x}} \mathrm{Fe}_{12-2 \mathrm{x}} \mathrm{O}_{19}$ has two types of charge carriers, p-type and n-type. The two types participate in the conduction process. The electronic exchange between $\mathrm{Fe}^{2+}$ and $\mathrm{Fe}^{3+}$ ions, between $\mathrm{Ti}^{3+}$ and $\mathrm{T}^{4+}$ ions and hole transfer between $\mathrm{Co}^{3+}$ and $\mathrm{Co}^{2+}$ ions at equivalent crystallographic sites (especially B-sites) are responsible for the conduction in ferrite according to Varwey de Boer mechanism $[12,13]$. The impurities $\mathrm{Co}^{3+}, \mathrm{Ti}^{3+}$ and

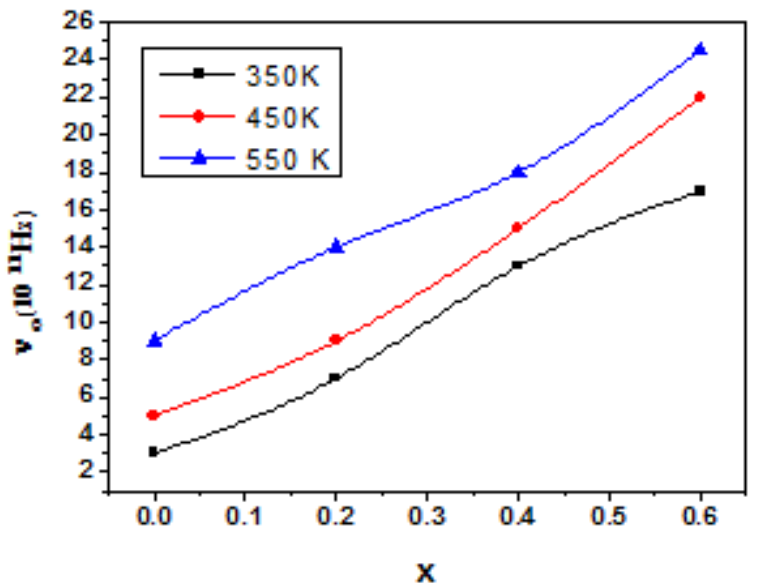

Figure 5: Variation of phonon frequency with with composition and temperature for $\mathrm{Ba}_{1-\mathrm{x}} \mathrm{Zn}_{\mathrm{x}} \mathrm{Co}_{\mathrm{x}} \mathrm{Ti}_{\mathrm{x}} \mathrm{Fe}_{12-2 \mathrm{x}} \mathrm{O}_{19}$ hexaferite.

$\mathrm{Fe}^{2+}$ ions could be formed during the sintering process [14, 15]. The conductivity can be expressed as: $\sigma=\sigma_{\mathrm{e}}+\sigma_{\mathrm{h}}=$ ne $\mu_{\mathrm{n}}+$ pe $\mu_{\mathrm{p}}$, where $\mu_{\mathrm{n}}$ and $\mu_{\mathrm{p}}$, are the mobility of electrons and holes, $\mathrm{n}$ and $\mathrm{p}$ the concentration of electrons and holes, respectively. p-type conduction is predominantly due to holes as a result of the reduction in Co contents in the $\mathrm{Ba}_{1-}$ ${ }_{\mathrm{x}} \mathrm{Zn}_{\mathrm{x}} \mathrm{Co}_{\mathrm{x}} \mathrm{Ti}_{\mathrm{x}} \mathrm{Fe}_{12-2 \mathrm{x}} \mathrm{O}_{19}$ system. Using DC conductivity and thermoelectric power data the drift mobility was determined as a function of temperature. Fig. 4 shows the temperature dependence of the charge carrier mobility (as Ln $\mu$ vs. $10^{3} / \mathrm{T}$ ) for all the studied samples. It is clear that $\mu$ increases as the temperature increases. This means that the predominance conduction mechanism is the hopping of localized charge carriers which activated by temperature. From the slopes of $\mu(\mathrm{T})$ the activation energy for hopping $\Delta \mathrm{E}$ was determined by the relation: $\mu=\mu_{\mathrm{o}} \exp \left(-\Delta \mathrm{E} / \mathrm{k}_{\mathrm{B}} \mathrm{T}\right)$, and listed in Table 1, where $\mu_{o}$ is a constant representing the mobility at $\mathrm{T}=\infty$ [16]. From the table we notice that, the activation energy $\Delta \mathrm{E}$ have all the samples have low values $(<$ $0.3 \mathrm{eV}$ ). According to Purushotham [17] and Klinger [18] for these samples the hopping of the small polaron cannot participate in the conduction mechanism and the hopping of the localized charge carriers is the principle conduction channel for the system.

\subsection{Effect of Composition and Temperature on Phonon Frequency $\left(v_{0}\right)$}

The phonon frequency, $v_{\mathrm{o}}$, was estimated from the small polaron mobility expression:

$$
\mu=\left[(1-c) \cdot e^{2} L^{2} v_{0} / k_{B} T\right] \exp \left(-E_{H} / k_{B} T\right)
$$

Where "e" is the electron charge, "c" velocity of light and $\mathrm{L}$ is the jump length between conduction sites calculated from the relation [7]:

$$
\mathrm{L}=\mathrm{d} \sqrt{ } 2 / 4
$$

where $d$ is the value of lattice parameters in the three directions for hexagonal ferrite, and $\mathrm{E}_{\mathrm{H}}$ is the activated hopping energy, $\mathrm{k}_{\mathrm{B}}$ Boltzmann constant. The effect of composition on the phonon frequency at different temperatures is shown in Fig. 5. It is noticed that the frequency increased with temperature and compositional parameter $\mathrm{x}$. These results can be explained as follows: the thermal conductivity of a material determined by a process may be considered a fundamental property of the material, and called the lattice conductivity. Imperfections and inhomogeneity in a body also acts as centers of phonon scattering, and thus further reducing in their mean free path. It is convenient to consider imperfections on the atomic scale, e. g. impurity atoms, dislocations and pores. The increase in the number of pores decreased the thermal conductivity and increased the phonon frequency, these pores scattered the phonons and reduced the mean free path, causing the increase in the phonon frequency $[19,20]$.

\section{Conclusion}

The results of this study can be summarized in the following points:

1) The system with the chemical formula $\mathrm{Ba}_{1-\mathrm{x}} \mathrm{Zn}$. $\mathrm{Co}_{\mathrm{x}} \mathrm{Ti}_{\mathrm{x}} \mathrm{Fe}_{12-2 \mathrm{x}} \mathrm{O}_{19}(0 \leq \mathrm{x} \leq 0.6)$ was prepared by ceramic method and XRD analysis confirmed the single phase magnetoplumbite structure.

2) The increase of thermal conductivity with increasing temperature in the system due to the increase in lattice vibration. This vibration enhances the thermal phonons to move through the samples.

3) The thermo-electric power measurements reveal the ptype semiconductor behavior of the samples.

4) The increasing in the mobility of localized charge carriers with the temperature indicated that the hopping of the charge carriers is the predominant conduction mechanism.

5) The increasing in the pores causes the decrease in

\section{Volume 4 Issue 11, November 2015}




\section{International Journal of Science and Research (IJSR) \\ ISSN (Online): 2319-7064}

Index Copernicus Value (2013): 6.14 | Impact Factor (2014): 5.611

thermal conductivity and increasing phonon frequency for the samples.

\section{Acknowledgements}

The author is thankful to Prof. Dr. S.M. Attia and Prof. Dr. M. El-Saadawy for the valuable discussions and providing many of the experimental facilities during this work.

\section{References}

[1] B. Viswanathan and V.R.K. Murthy. Ferrite Materials Science and Technology, Narosa Publishing house, New Delhi, 1990..

[2] D. Stoppels. "Developments in soft magnetic power ferrites". Journal of Magnetism and Magnetic Material, 160, pp. 323-328, 1996.

[3] H. Kojima. Fundamental Properties of Hexagonal Ferrites In Ferromagnetic Materials, Wohlfahrt (Ed.), Vol. 3, North-Holland, Amsterdam, 1982.

[4] X. Liu, J. Wang, Leong-Ming Gan, Sen-Choon Ng and J. Ding. "An ultrafine barium ferrite powder of high coercivity from water-in-oil microemulsion". Journal of Magnetism and Magnetic Material, 184, pp. 344- 350, 1998.

[5] P. Wartewig, M. K. Krause, P. Esquinazi, S. Rosler and R. Sonntag, "Magnetic properties on $\mathrm{Zn}$ - and $\mathrm{Ti}$ substituted barium hexaferritr Journal of Magnetism and Magnetic Material”, 192 (1), pp. 83- 99, 1999.

[6] M.R. Eraky "Electrical conductivity of cobalt- Titanium substituted SrCaM hexaferrites". Journal of Magnetism and Magnetic Material, 324, pp. 1034-1039, 2012.

[7] M.R. Eraky and S.M. Attia "Transport properties of TiNi spinel ferrites”. Physica B, 462, pp. 97- 103, 2015.

[8] Z.Q. Jin and J.P. Lin, “ Rapid thermal processing of magnetic materials". Journal of Physics. D: Appl. Phys., 39, pp. 227- 244, 2006.

[9] Z.S. Shan, J.P. Liu, V.M. Chkka, H. Zeng and J.S. Jiang, "Energy barrier and magnetic properties of exchange -coupled hard -soft bilayer", IEEE Translation Journal on Magnetics in Japa., 38 (5), pp. 2907- 2909, 2002.

[10] Z.J. Guo, J.S. Jiang, J.E. Pearson, S.D. Bader and J.P. Liu, "Exchange-coupled $\mathrm{Sm}-\mathrm{Co} / \mathrm{Nd}-\mathrm{Co}$ nanomagnets: correlation between soft phase anisotropy and exchange field", Applied Physics Letter, 81, pp.2029- 2031, 2002.

[11] J.S. Jiang et al., Applied Physics Letter, 85, pp. 52935295. 2004.

[12] E.J.W. Verwey and J.H. de Boer, " Semi-conductors with partially and with completely filled 3d-lattice bands" Proceedings of the Physical Society, 49, pp. 5971, 1937.

[13] E.J. Verwey, and J. H. De Boer, Rec. Trans. Chim. Des. Phys. Bas., 55, pp. 531, 1936.

[14] F.K. Lotering, Journal of Physics and Chemistry of Solids, 25, pp. 95, 1964.

[15] A.A. Gham, S.A. Mazen and A.H. Ashour, Physica Status Solidi: A, 84, pp. 337, 1984.

[16] A. Collomb, et al., " Magnetic properties of $\mathrm{Ba}_{2} \mathrm{Cu}_{\mathrm{x}} \mathrm{Zn}_{1 \text { - }}$ ${ }_{x} 2 \mathrm{Fe}_{28} \mathrm{O}_{46}$ X-type hexagonal ferrite". Fourth international Conference on ferrite, Part 11. San Francisco, Ca (USA) pp. 55, 1985.

[17] Y. Purushotham, P. Kishan, N. Kumar and P.V. Reddy, Materials Letters, 22, pp. 47, 1995.

[18] M.I. Klinger, Journal of Physics C, 8, pp. 3595, 1975.

[19] H. Ohno, et al., Physical Review Letters, 68, pp. 26642667, 1992 .

[20] A. Kojima, A. Makino and A. Inoue, Journal of Applied Physics, 87, pp. 6576- 6578, 2000.

\section{Author Profile}

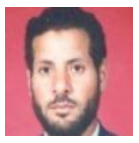

M. R. Eraky received the B.Sc. from Faculty of Science. Tanta University (in Physics) and M.Sc. Degrees in High Energy Physics from Cairo Univ. Egypt in 1981 and 1998, respectively. During 19901995 , he received $\mathrm{Ph}$. D. degree in NMR and magnetic relaxation in $\mathrm{M}$ hexaferrite. 